\title{
METODOLOGIA DO SERVIÇO DO ATENDIMENTO EDUCACIONAL ESPECIALIZADO EM UMA PERSPECTIVA INCLUSIVA NA ESCOLA REGULAR
}

\author{
METODOLOGÍA DEL SERVICIO DEL ATENDIMIENTO EDUCACIONAL \\ ESPECIALIZADO EN UNA PERSPECTIVA INCLUSIVA EN LA ESCUELA \\ REGULAR
}
METHODOLOGY OF SPECIALIZED EDUCATION SERVICES UNDER AN INCLUSIVE PERSPECTIVE IN REGULAR SCHOOLS

\author{
Mirlene Ferreira Macedo DAMÁZIO ${ }^{1}$
}

RESUMO: O presente artigo tem por objetivo dialogar sobre a educação especial em uma perspectiva inclusiva, com enfoque na metodologia do serviço de atendimento educacional especializado (AEE) em escola de ensino regular. Esta pesquisa ação crítico colaborativa, cujo objetivo é investigar cooperativamente metodologias do serviço e do ensino, procurando compreendê-los. O projeto é aplicado e desenvolvido por quatorze profissionais que atuam no AEE das escolas de Ensino Fundamental de Dourados/MS, sendo oito municipais, quatro estaduais e dois de universidade, que oferecem serviço especializado. A pesquisa está em processo de aplicação e seus resultados são parciais. Existem muitas confusões e controvérsias sobre o "como" realizar o serviço do AEE dentro da escola comum em uma perspectiva inclusiva. Apresentamos aqui questões importantes incitadas pela primeira etapa da pesquisa envolvendo a metodologia do serviço e os equívocos sobre o AEE, a SRM e a Educação Especial.

PALAVRAS-CHAVE: Atendimento educacional especializado. Metodologia. Ensino regular. Inclusão.

RESUMEN: El presente artículo tiene por objetivo dialogar sobre la educación especial en una perspectiva inclusiva, con enfoque en la metodología del servicio de atención educativa especializada (AEE) en escuela de enseñanza regular. Esta investigación acción crítica colaborativa, cuyo objetivo es investigar cooperativamente metodologías del servicio y de la enseñanza, procurando comprenderlos. El proyecto es aplicado y desarrollado por catorce profesionales que actúan en el AEE de las escuelas de Enseñanza Fundamental de Dourados/MS, siendo ocho municipales, cuatro estaduales y dos de universidad, que ofrecen servicio especializado. La investigación está en proceso de aplicación y sus resultados son parciales. Hay muchas confusiones y controversias sobre el "cómo" realizar el servicio del AEE dentro de la escuela común en una perspectiva inclusiva. Por tanto, en el presente artículo, presentamos cuestiones importantes impulsadas por la primera etapa de la investigación involucrando la

${ }^{1}$ Universidade Federal da Grande Dourados (UFGD), Dourados - MS - Brasil. Professora Adjunta, Faculdade de Educação. Pedagoga, mestre e doutora em Educação. ORCID <https://orcid.org/0000-0001-7449-2261>.E-mail: mirlenedamazio@ufgd.edu.br

RPGE- Revista on line de Política e Gestão Educacional, Araraquara, v. 22, n. esp. 2, p. 840-855, dez., 2018. E-ISSN:1519-9029. 
metodología del servicio y los equívocos sobre el AEE, la SRM y la Educación Especial.

PALABRAS CLAVE: Atención educativa especializada. Metodología. Enseñanza regular. Inclusión.

ABSTRACT: This article aims to discuss Special Education under an inclusive perspective, focusing on the methodology of Specialized Education Services (SES) in regular schools. The objective of this critical-collaborative action research is to cooperatively investigate service and teaching methodologies in order to understand them. The project is implemented and developed by fourteen professionals who work in the SES of elementary schools based in Dourados/MS. Eight schools belong to the town, four of them belong to the State and two of them are part of the University, which offers specialized services. The research is in process of application and its results are partial. There are many confusions and controversies about the "how" to carry out the SES within a regular school under an inclusive perspective. Therefore, we present important questions prompted by the first stage of the research involving the methodology of the services and the misconceptions about the SES, MRR and Special Education.

KEYWORDS: Specialized education services. Methodology. regular Education. Inclusion.

\section{Introdução}

A educação especial, em uma perspectiva inclusiva, é um paradigma fundamentado na concepção de direitos e valores humanos, que agrega infinitas possibilidades para as pessoas com deficiência (PcD), transtornos globais do desenvolvimento (TGD) e altas habilidades/superdotados (AH/SD), compreendendo, em especial, o acesso e a permanência no âmbito escolar com igualdade e equidade.

O Brasil enfrenta um grande desafio, o de se organizar para se tornar um país que acolhe e respeita as diferenças humanas, valorizando seus potenciais individuais e coletivos, relegando o caráter excludente, discriminatório e segregacionista, em especial na escola de ensino regular. Para efetivar esse processo é necessário enfrentar os empecilhos e os entraves existentes, envolvendo os bens, serviços, atitude ou comportamento que estabeleçam impedimentos à plena ação de cidadania de qualquer pessoa. Tornar o espaço da escola brasileira inclusivo impõe mudanças de paradigmas e exige novos “jeitos" de fazer escola, ou seja, mudar a concepção da estrutura/funcionamento das práxis pedagógicas.

A Lei Brasileira de Inclusão 13.146/2015 (LBI/2015) garante vários direitos aos 45 milhões de brasileiros com PcD, TGD e AH/SD e estabelece sanções para atitudes 
preconceituosas e discriminatórias. Pelo texto da LBI/2015, que tem como base a Convenção da ONU sobre os Direitos das Pessoas com Deficiência, questões relacionadas à acessibilidade, à educação e ao trabalho passaram a ser mais discutidas, e um dos principais avanços é a inclusão social e escolar. Outro aspecto relevante e inovador está no conceito legitimado de deficiência, que agora não é mais entendida como uma condição estática e biológica da pessoa, e sim como o resultado da interação das barreiras impostas pelo meio com as limitações de natureza física, mental, intelectual e sensorial do indivíduo. A deficiência deixa de ser um atributo da pessoa e torna-se o resultado da falta de acessibilidade que a sociedade e o Estado dão às características de cada um.

Ao se pensar na Política Nacional de Educação Especial na Perspectiva da Educação Inclusiva de 2008, reformulada em 2011, percebe-se progresso nas políticas públicas e nas leis que a amparam, mas as modificações estruturais e atitudinais nas escolas ainda estão longe de representá-las e deixam muito a desejar. As leis são necessárias para assegurar os direitos, porém a mudança de mentalidade, envolvendo os novos paradigmas educacionais da contemporaneidade, precisa ser incitada, criando movimentos que alterem o cenário, e isso é urgente. Para tanto, algumas tomadas de posição e compreensão de bases epistemológicas de caráter inclusivo precisam ficar mais claras para que as escolas apresentem propostas efetivas e produtivas. Muitos são os empecilhos e entraves, mas as possibilidades e alternativas são infinitas e dependem da capacidade que temos para mudarmos o jeito de fazer a escola brasileira, iniciando pela formação de professores.

Nesse contexto, a atenção deve estar centrada primeiramente no potencial natural que os seres humanos têm, independentemente de deficiência ou diferença. No caso específico das pessoas com PcD, TGD e AH/SD, se ambientes forem criados para que eles possam desenvolver o seu potencial, outras questões serão secundarizadas. Compreendemo-los como seres dialógicos, transformacionais, inconclusivos, reflexivos, síntese de múltiplas determinações em um conjunto de relações sociais, como um ser que possui diferenças e capacidades de idealizar e de criar, ter a capacidade de reinventar os caminhos até hoje praticados em favor de seu processo educacional e criar um novo lócus de vida (DAMÁZIO; ALVES, 2010, p. 49).

É necessário reinventar as formas de conceber a escola e suas práticas pedagógicas, rompendo com os modos lineares do pensar e agir no que se refere às 
formas de organizarmos as propostas político-pedagógicas e sua matriz curricular. Assim, para contemplarmos a superação dos modos lineares de pensar e agir, um caminho inovador e possível perpassa a adoção dos princípios do desenho universal. De acordo com Carletto e Cambiaghi (2016, p. 10), “o desenho universal é o processo de criar os produtos e processos que são acessíveis para todas as pessoas, independente de suas características pessoais, idades, ou habilidades".

Nesse sentido, a adoção e aplicação do desenho universal para a aprendizagem iniciam pelo currículo escolar. A construção do currículo seguindo os princípios do desenho universal tem como pressuposto e objetivo atender aos alunos de formas distintas, com suas diferenças socioculturais e econômicas, respeitando como percebem e compreendem o conhecimento. Segundo Nunes e Madureira (2010, p. 6-7), "assegurar a participação e o sucesso na aprendizagem envolve mudanças significativas nas formas de conceber a função da escola e o papel do professor no processo de ensino e aprendizagem". Assim, a escola que fundamenta suas práticas no desenho universal entende que o currículo deve acompanhar as diferentes necessidades e realidades.

Diante do exposto, é imprescindível rompermos com a visão cartesiana de gestar currículo, seu modelo linear, hierarquizado, homogêneo, disciplinar baseado em deduções, sem considerar a subjetividade eminente que envolve o meio ambiente e as pessoas. Sob outra perspectiva, em uma visão do desenho universal, sistêmico, temos uma concepção ampliada, em que as conexões, as interatividades e a interdependência dos fenômenos provocam trocas, as complementaridades das ações humanas criando formas e jeitos de fazer diferente, considerando a importância de observar o ser humano e suas interações nos variados contextos e sistemas. Assim, o problema é visto no processo, no contexto, na pessoa e no tempo vivido (BRONFENBRENNER, 1979).

Dessarte, Bronfenbrenner (1979) ressalta que o ser humano é protagonista e ativo em seu desenvolvimento, rompendo com as ideias que concebem o ser humano como passivo que apenas recebe influências do ambiente sem nele poder intervir. Essa abordagem nos leva a uma visão sistêmica do ser humano, abrangendo o genético, o comportamental e o ambiental, ou seja, físico, social e cultural, que se integram ao longo do tempo, em contexto, história de vida, rotinas e processos, isto é, uma ampla compreensão de sistemas interdependentes que agem dinamicamente e exercem influência sobre o desenvolvimento humano. Nessa perspectiva, evidenciam-se princípios que coadunam com o fazer do desenho universal para a aprendizagem. 
Nesse contexto, precisamos desenvolver um campo de trabalho comprometido com a formação e desenvolvimento das pessoas, visando possibilitar-lhe um convívio com a realidade, de maneira contextualizada, compreendendo seus aspectos condicionantes e ideológicos e propondo possíveis alternativas às questões-problemas que deflagram as habilidades para interpretar o mundo na visão da virtualidade, da sustentabilidade, da inteireza, da plenitude e da visão ecológica; ver o homem no mundo como um fenômeno complexo, no qual a incerteza, a indefinição, a incompletude, a complementaridade são elementos para sua reflexão/ação; compreender ideias e valores socioculturais e históricos, indispensáveis aos atos do homem no mundo; apreender o conhecimento e as coisas do mundo de maneira conectada e contextualizada, construindo significados, sentidos e aplicabilidade na vida; inter-relacionar os saberes adquiridos com os fazeres cotidianos, buscando avanços individuais e coletivos; criar e recriar conhecimentos que são direta e indiretamente relacionados aos atos humanos e seu bem viver (DAMÁZIO, 2010).

Nesse aspecto, a atenção recai permanentemente no aproveitamento de toda e qualquer possibilidade existente na pessoa, visando favorecer a oportunidade de ela ser o que poder ser, e não o que queremos que ela seja compreendida pelos padrões de normalidade e nas respostas esperadas e determinadas. Portanto, o ambiente de aprendizagem é organizado a partir do pressuposto de que todas as pessoas são diferentes e, por isso, são necessárias atitudes e posturas de respeito às limitações e potenciais de todos, inclusive das pessoas com diferenças humanas provocadas pelas deficiências, transtornos e altas habilidades/superdotação.

Diante do exposto, e tendo como foco de nosso estudo a Educação Especial na perspectiva inclusiva, realizamos desde 2017 uma pesquisa denominada Passo a Passo: metodologia do Atendimento Educacional Especializado, visando investigar colaborativamente as metodologias gerais do serviço e do ensino, procurando compreendê-los e, se possível, gerar soluções inovadoras práticas, simples e objetivas, extraídas do cotidiano e referendadas pelas bases epistemológicas concernentes à inclusão. Para tanto, adotamos a pesquisa ação crítico-colaborativa como metodologia científica para a execução do presente projeto. Essa metodologia considera a "voz do sujeito, sua perspectiva, seu sentido, mas não apenas para registro e posterior interpretação do pesquisador, a voz do sujeito fará parte da tessitura da metodologia da investigação" (FRANCO, 2005, p. 486). 
O projeto é aplicado e desenvolvido por quatorze profissionais especializados que atuam no AEE das escolas municipais, estaduais de Ensino Fundamental da cidade de Dourados/MS, bem como no ensino superior - sendo oito municipais, quatro estaduais e dois de universidade, que oferecem serviço especializado. Denominamos na pesquisa a figura dos pesquisadores professores da universidade e pesquisadores professores das escolas, criando uma forma de tratamento que representasse a metodologia da pesquisa, ou seja, todos os que trabalham são participantes, um coletivo. Os pesquisadores professores da universidade e pesquisadores professores das escolas trabalham de forma participante, coletiva e observadora, investigando os serviços do atendimento especializado e suas metodologias de ensino, e, a partir desse cenário, analisam as possibilidades de aperfeiçoamento do trabalho metodológico. Portanto, o professor pesquisador da escola atuará realizando autoinvestigação dos serviços que executa no AEE e suas metodologias de ensino, e o professor pesquisador da universidade ajudará com a medicação científica, ao mesmo tempo que constrói com o pesquisador professor da escola um campo conceitual importante para a autoinvestigação.

Durante o percurso investigativo, compreendemos o desenvolvimento humano, considerando as capacidades diferenciadas para cada momento do ato de ensinar a aprender a aprender, respeitando os princípios pedagógicos, a seguir descritos: autoridade do professor baseada numa relação de respeito e responsabilidade; observação do estudante como eixo íntimo para a construção contextual-relacionalvivencial do ambiente de aprendizagem; heterogeneidade, singularidade, como pilares de compreensão da individualidade e das diferenças humanas; respeito aos ciclos naturais de desenvolvimento humano; consideração do conhecimento como energia viva, dissipadora, que provoca movimento transformacional continuado e recursivo da pessoa com o meio e vice-versa; aprendizagem compreendida como processo vivencial contextual, sintônico, construída por meio de ambientes estimuladores do aprender a aprender e metodologia de ensino considerada como caminho interior, no qual o aprender a aprender possibilita a auto-organização e a aquisição de habilidades essenciais (DAMÁZIO, 2010).

Como a pesquisa está em processo, apresentaremos neste artigo a primeira etapa, visando elucidar aspectos interessantes já evidenciados. A primeira etapa configurou-se como a organização da pesquisa nas escolas municipais e estaduais de ensino. Nessa etapa, entramos em contato com os dirigentes dos sistemas públicos municipais e 
estaduais para os trâmites administrativos gerenciais da pesquisa, envolvendo a apresentação geral da pesquisa, o cadastro das escolas envolvidas e de seus professores. Esses professores são denominados na pesquisa professores pesquisadores na escola (PPE). Cada escola e seus professores foram cadastrados em formulário próprio construído para esse fim. Abordamos no cadastro dados pessoais, profissionais e indagamos a cada PPE como ele realizava a metodologia do serviço do AEE?

Responderam os questionários 12 professores. Ao analisarmos as 12 respostas, percebemos que os professores do AEE consideravam a metodologia do serviço como a metodologia do ensino, pois explicavam exatamente como trabalhavam, ou seja, atuavam o tempo todo atendendo os alunos e não realizavam outras ações do serviço do AEE de acordo com o Decreto n. ${ }^{\text { }} 7.611$, de 17 novembro de 2011, que dispõe sobre a Educação Especial, o Atendimento Educacional Especializado e dá outras providências.

Vejamos algumas respostas que retrataram a síntese das demais:

"Realizo o serviço atendendo os alunos na SRM, em horários definidos no turno ou no contraturno, visto que muitos alunos os pais não os trazem no contraturno. Faço os atendimentos individualmente ou em pequenos grupos duas vezes por semana, durante 4 horas na "em" (PPE-O1).

"O meu serviço é atender individualmente e ou em grupos os alunos com PcD, TGD e adequar recursos pedagógicos na sala de recurso multifuncional (SRM). Geralmente atendo no contraturno, mas temos alunos que não vêm no contraturno por problema de transporte. Faço o plano de desenvolvimento individual de cada um da SRM" (PPE02).

Ao analisarmos as respostas, ficou perceptível um equívoco conceitual e operacional com relação ao que é o AEE e o que é a Sala de Recursos Multifuncionais (SRM).

A SRM é um espaço físico localizado na escola onde também se realiza o AEE, ou seja, não é o único local em que esse serviço acontece e muito menos o que o define. A SRM trata-se de um espaço com mobiliário, materiais didáticos e pedagógicos, recursos de acessibilidade e equipamentos específicos. A SRM não é o serviço, ou seja, não é o AEE. A SRM é um dos espaços designados na escola para realizar as atividades do AEE, porém não pode ser confundido com a metodologia do serviço e do ensino praticado no AEE (DAMÁZIO, 2010).

Diante do exposto, percebemos que os serviços do AEE ficaram concentrados em atender os alunos, fazer plano de AEE e adequar recursos na SRM. Entretanto, o 
Decreto-lei n. ${ }^{\circ}$ 7.611/2011 estabelece que o AEE tem como objetivo garantir a participação, o acesso, a permanência e a aprendizagem desses estudantes nas escolas de ensino regular, promovendo respostas às suas necessidades específicas e garantindo a transversalidade da educação especial, bem como o envolvimento com a família e a intersetorialidade com a comunidade.

A legislação brasileira objetiva oferecer um sistema educacional inclusivo, gratuito, compulsório em todos os níveis de ensino, sem discriminação, com base na igualdade de oportunidades ao público-alvo da educação especial, resguardando o aprendizado ao longo de toda a vida de forma acessível, contemplando efetiva aprendizagem de acordo com as necessidades específicas e individuais, com adoção de medidas de apoio individualizado que maximizem o desenvolvimento acadêmico e social. Assim, o AEE deve apoiar o desenvolvimento do estudante, disponibilizando o ensino de linguagens e códigos específicos de comunicação e sinalização, de tecnologia assistiva, adequar e produzir materiais didáticos e pedagógicos, tendo em vista as necessidades específicas dos estudantes, oportunizando complementação e suplementação curricular (BRASIL, 2011).

Esse serviço ofertado exige formação e atuação diferenciada dos professores, envolvendo conhecimentos específicos, tais como: Língua de Sinais Brasileira (Libras), Língua Portuguesa na modalidade escrita, como segunda língua para pessoas com surdez; sistema braille, sorobã, orientação e mobilidade, utilização de recursos ópticos e não ópticos; atividades de vida autônoma; tecnologia assistiva; processo de ensino e aprendizagem norteados pelas funções mentais superiores; adequação e produção de materiais didáticos pedagógicos; acolhimento e elaboração de planos de AEE para estudantes com altas habilidades/superdotados com programa de suplementação curricular. Todas as ações envolvem a metodologia do professor para o serviço nas várias frentes dentro da escola e no ensino (BRASIL, 2011).

Nesse sentido, fomos incitados a investigar e verificar se esse entendimento se tratava de um equívoco local, regional ou mesmo nacional, e assim fizemos revisão na produção científica de 2009 até 2017, visando identificar como os estudos delineavam essa questão, ou seja, como compreendiam a metodologia do serviço do AEE em uma perspectiva inclusiva.

Realizamos uma ampla revisão na literatura científica sobre a temática, procurando contribuições ao estudo. O levantamento bibliográfico preliminar foi realizado a partir dos descritores: metodologia do serviço do AEE, metodologia de 
ensino no AEE. Realizamos a investigação no banco de dados de teses e dissertações da Coordenação de Aperfeiçoamento de Pessoal de Nível Superior (CAPES), na Biblioteca Digital Brasileira de Teses e Dissertações (BDTD), bem como em revistas, periódicos e livros que pudessem abordar a temática e metodologia do serviço do AEE.

A revisão na literatura de certa forma foi decepcionante, pois encontramos diversos estudos sobre o AEE envolvendo atendimento em todas as áreas, muitos trabalhos sobre a SRM designando-a como se fosse o AEE, e até a configuração da Educação Especial no sentido de ela ser o AEE. Isso caracteriza um erro conceitual e provoca deturpações nas ações realizadas pelo AEE.

Salientamos que todas as ações e atividades desenvolvidas pelo AEE diferenciam-se das que são realizadas em salas de aula comum segundo o Decreto-lei n. ${ }^{\circ}$ 7.611/2011. Sendo assim, realizamos a mediação científica com os professores pesquisadores da escola, esclarecendo conceitualmente quais os serviços e como eles podem e devem ser organizados de forma transversalizada, atendendo aos princípios da perspectiva inclusiva, Assim, exemplificamos 12 serviços importantes e essenciais de serem desenvolvidos em prol dos alunos, veja abaixo:

1. Acolhimento inicial e elaboração do plano de AEE de acordo com o perfil do aluno;

2. Atendimento individual ao aluno ou em subgrupo na SRM;

3. Adequação de material pedagógico e tecnologia assistiva (TA);

4. Apoio e assessoria ao estudante na sala de aula comum de ensino regular;

5. Apoio e assessoria ao professor de classe comum;

6. Apoio e assessoria ao professor de Artes e Educação Física;

7. Apoio e assessoria ao professor de apoio escolar;

8. Apoio e assessoria aos monitores, cuidadores e/ou estagiários;

9. Apoio e assessoria aos gestores (direção e coordenação);

10. Apoio e orientações à família;

11. Ações intersetoriais - saúde e ação social;

12. Elaboração de pareceres e relatórios descritivos analíticos de cunho pedagógico.

É possível compreender que a atuação do profissional do AEE, em ações inclusivas, não envolve apenas atender ao estudante individualmente na sala de recurso multifuncional (SRM) em uma visão segregada, e, sim, realizar interlocuções com os demais profissionais e setores da escola de forma direta ou indireta em favor do desenvolvimento dos alunos com PcD, TGD e AH/SD. Entendemos que, se o professor especializado atuar somente em uma das ações mencionadas, ele não conseguirá realizar o serviço em uma perspectiva inclusiva como prescreve a política, reproduzindo mais 
uma vez a concepção segregada e/ou integracionista. Portanto, é preciso compreender que o AEE, como um serviço da Educação Especial deve contemplar a transversalidade, complementaridade, interlocuções e conexões, ou seja, a visão sistêmica é o mote deflagrador da ação metodológica do serviço do AEE oferecido na escola de ensino regular.

Outra questão bastante relevante de ser colocada é a definição de professor multifuncional, associando o professor do AEE à função exclusiva na SRM em que ele somente faz atendimento de alunos nesse espaço ou adéqua materiais. Sabemos que alguns documentos orientadores geraram entendimentos diversificados e até equivocados sobre o serviço, porém se consideramos que, ao falarmos de inclusão, situamos-nos de forma diferente epistemologicamente, e de imediato descartamos qualquer visão dicotomizada, segregada.

O professor especialista em Educação Especial, atuando no serviço do AEE em uma perspectiva inclusiva na escola de ensino regular, vem para estabelecer um serviço inclusivo e não segregado dentro da escola. Ele atua em função do serviço de forma geral, como um articulador, mediador e interlocutor, realizando o que é necessário ao serviço especializado, sem substituir o professor de classe comum. Portanto, vamos compreender, algumas ações que foram elencadas ao serviço do professor do AEE em uma perspectiva inclusiva dentro da escola de ensino regular comum. Veja a seguir:

\section{Acolhimento inicial e elaboração do plano de AEE de acordo com o perfil do aluno}

Ao ser matriculado na escola, o estudante é identificado pelo gestor da escola, que deve comunicar ao professor do AEE, garantindo incialmente o acolhimento. $\mathrm{O}$ acolhimento que consiste em dar ao estudante a oportunidade de se situar no novo espaço, bem como identificar as necessidades básicas de alimentação, higiene, locomoção e comunicação, promovendo a socialização inicial. Nesse momento, iniciase a coleta de dados para a elaboração do plano de AEE. Geralmente, o professor do AEE necessita de 45 dias para reunir dados, sistematizá-los, concluir e especificar as necessidades do estudante no plano de AEE. O plano de AEE é um documento extremamente importante que asseguram direitos e deveres aos profissionais e estudantes. Ele norteará todo o processo que deverá ser construído e aplicado em favor 
do estudante, envolvendo recursos humanos e materiais. É prudente que o plano de AEE seja revisado de seis em seis meses, garantindo o pleno acompanhamento do estudante.

\section{Atendimento individual ao aluno ou em subgrupo na SEM}

Esse atendimento é definido a partir o plano de AEE, ou seja, deve constar qual tipo de atendimento o estudante precisará: individual ou em subgrupo na SRM. Ao ser caracterizado, ficam evidenciados o perfil do estudante e as necessidades específicas. Ao atender individualmente ou em subgrupo, o professor delineia a prática pedagógica a ser aplicada, envolvendo principalmente as funções mentais superiores. Essas funções delinearão o atendimento especializado, procurando dar subsídios complementares ou suplementares ao trabalho do professor na classe comum.

\section{Adequação de material pedagógico e tecnologia assistiva (TA)}

Outro aspecto importante a ser contemplado no plano de AEE é a necessidade dos estudantes com alguma TA. É responsabilidade do professor avaliar pedagogicamente o estudante e buscar apoio inter setorial com outras áreas, visando a avaliação funcional para definir qual TA se aplica e, em seguida, preparar e orientar o estudante para usá-la. Inicia-se o trabalho preparando-o para o uso da TA em sala de aula e demais espaços. O professor do AEE tem responsabilidade por esse processo de adequação pedagógica, envolvendo tecnologia de baixa ou alta resolução.

\section{Apoio e assessoria ao estudante na sala de aula comum de ensino regular}

O apoio e assessoria do professor do AEE ao estudante com deficiência, TGD e AH/SD dentro da sala de aula comum englobam um olhar completo das necessidades dele já descritas no plano de AEE. O professor vai apoiar e assessorar o estudante em questões específicas de cunho pedagógico compreendendo o uso de TA, código de linguagens e a sua aprendizagem, dedicando atenção aos estilos de aprendizagem. Ele vai assessorar o estudante em sua organização didática e dar orientações aos atos de estudo. Esse processo é dinâmico e o professor deve percorrer cotidianamente as salas e apoiar, assessorar qualquer situação que o envolva em sala de aula; afinal, tudo o que o AEE faz é para complementar o trabalho da classe comum, ou seja, atingir os objetivos educacionais, ajudando-o a evoluir em seu percurso escolar. 


\section{$5 \mathrm{O}$ apoio e a assessoria ao professor de classe comum}

O apoio e a assessoria do professor do AEE ao professor de classe comum configuram-se como um trabalho cotidiano e sistemático, a partir do plano de AEE do estudante. O professor do AEE auxilia o professor de classe comum com o uso de TA, orientação e mobilidade, linguagens e adequação pedagógica de atividades e provas. $\mathrm{O}$ professor de classe comum também é instruído sobre a melhor forma de conduzir o trabalho do professor de apoio escolar, monitor, cuidador e/ou estagiário que o esteja ajudando na turma. Esse auxílio que o professor de classe comum recebe de outros profissionais dentro da sala é complexo e envolve uma dinâmica pedagógica diferenciada, primando pela autonomia, independência e desenvolvimento de todos os estudantes, particularmente do público-alvo da educação especial.

$\mathrm{O}$ professor do AEE orienta o professor de classe comum sobre como sensibilizar a turma a uma boa convivência com as diversas diferenças, resguardando a interação social para todos. No tocante à posição de "onde se sentar" na sala de aula, isso não é rígido, mas deve primar pela necessidade específica do $\mathrm{PcD}$, TGD e AH/SD e a boa interação com todos os colegas. A turma é sempre observada em seu todo e a disposição deve valorizar diversificadas formas para desenvolver uma ambiência pedagógica colaborativa e interativa.

\section{Apoio e assessoria ao professor de Artes e Educação Física}

O apoio e a assessoria do professor do AEE ao professor de Educação Física e Artes caracterizam-se também como um trabalho cotidiano e sistemático, a partir do plano de AEE do estudante. O professor de AEE acompanhará a metodologia, os procedimentos e os recursos de ensino escolhidos e utilizados pelo professor da aula especializada, levando-o a refletir sobre a melhor forma de participação do estudante, ou seja, em um jogo interativo ou em uma expressão criadora da arte. O professor do AEE estimulará o professor a buscar formas diferenciadas para contemplar o potencial dos estudantes com PcD, TGD e AH/SD no contexto dessas disciplinas, envolvendo o como participar, interagir e expressar.

\section{Apoio e assessoria ao profissional de apoio escolar}


O apoio e a assessoria do profissional de apoio escolar acontece desde a definição da necessidade desse profissional para a turma que tem alunos com necessidades específicas. Ao iniciar o trabalho, esse professor deve ser acolhido pelo professor do AEE que vai dar toda a orientação a partir do plano do AEE, atendendo às necessidades específicas do aluno. O professor orienta o acolhimento do aluno, sistema de comunicação, orientação, mobilidade e adequações pedagógicas. Realiza acompanhamento sistemático, esporádico e de acordo com a necessidade desse profissional, assegurando que o trabalho promova a autonomia e a independência do aluno.

\section{Apoio e assessoria aos monitores, cuidadores e/ou estagiários}

O apoio e a assessoria aos monitores, cuidadores e/ou estagiários ocorrem desde a definição da necessidade desse profissional e/ou estagiário para a turma ou escola que têm alunos com necessidades específicas. Ao iniciar o trabalho, esses profissionais e/ou estagiários devem ser acolhidos pelo professor do AEE que vai iniciar toda a orientação a partir do plano do AEE, atendendo às necessidades específicas dos alunos. $\mathrm{O}$ professor orienta o acolhimento dos alunos, sistema comunicação, orientação/mobilidade e adequações pedagógicas. Realiza acompanhamento sistemático, esporádico e de acordo com a necessidade desses profissionais e/ou estagiários, assegurando que o trabalho promova a autonomia e a independência do aluno.

\section{Apoio e assessoria aos gestores (direção e coordenadores pedagógicos)}

O apoio e a assessoria do professor do AEE aos gestores acontecem desde o acolhimento desses alunos na escola, sua matrícula e a enturmação. As necessidades específicas dos alunos são definidas pelo plano de AEE e fornecerão todas as orientações aos gestores sobre a forma de conduzir as dimensões administrativas e pedagógicas, compreendendo recursos humanos, materiais, bem como os procedimentos pedagógicos específicos a serem adotados pelos funcionários envolvidos no trabalho. $\mathrm{O}$ professor do AEE tem a função, como profissional especialista da Educação Especial na escola, de promover a perspectiva inclusiva desses alunos. Ele realiza acompanhamento 
sistemático, esporádico e de acordo com a necessidade dos gestores, assegurando que o trabalho aconteça em favor dos alunos público- alvo da Educação Especial.

\section{Apoio e orientações à família}

Apoio e orientações à família ocorrem a partir do relato e estudo do caso. Considerando as necessidades apontadas no plano de AEE, o professor de AEE realiza orientações aos pais no sentido de juda-los na condução dos atos educativos em favor do filho. Todas as orientações são norteadas pelos aspectos definidos no plano de AEE. Espera-se, com esse apoio e orientação, que a família melhore os atos educativos em favor do filho e que o estudante ganhe em seu desenvolvimento, promovendo sua autonomia e independência.

\section{Ações intersetoriais - saúde e ação social}

O professor do AEE, a partir do momento que faz o acolhimento do estudante, inicia a coleta de dados sobre ele e, escreve e analisa o caso, organizando o plano de AEE, define se haverá ou não necessidade de apoio inter setorial com a saúde e ação social. Essas ações intersetoriais são previstas nas leis brasileiras, visando ações colaborativas de outros setores que cuidam também do desenvolvimento das PcD, TGD e AH/SD, garantindo saúde física, mental e bem-estar social.

\section{Elaboração de pareceres e relatórios descritivos analíticos de cunho pedagógico}

O professor do AEE tem como atribuição permanente a elaboração e emissão de pareceres e relatórios descritivos analíticos, visando oferecer informações, bem como sistematizar o trabalho desenvolvido. Cada instituição, com seu setor ou núcleos de Educação Especial, estabelece os modelos que serão seguidos pelos professores. O importante é que os pareceres e relatórios contemplem os seguintes aspectos relacionados ao desenvolvimento do estudante: cognição, afetividade, sociabilidade, linguagem, atenção e motricidade.

\section{Considerações finais}


Diante do exposto, essas doze ações descritas acontecem de forma sistemática e/ou esporádica no cotidiano da metodologia do serviço do trabalho do professor do AEE em uma perspectiva inclusiva. Se o professor atua apenas atendendo ao estudante na SRM e não realiza as diversas ações, ele faz o serviço de forma segregada, ou seja, a Educação Especial não estará em uma perspectiva inclusiva dentro da escola de ensino regular. Executar o serviço do AEE na perspectiva inclusiva não é transformar o professor em multifuncional, em "superprofissional" ou em alguém que se tornou "mil e uma utilidades", é ter a visão sistêmica norteando o serviço e evitando novamente a exclusão e a segregação desses estudantes.

Ao desenvolver o serviço do AEE em uma perspectiva inclusiva, o professor do AEE não transforma a escola excludente em inclusiva, mas colabora com a construção desse paradigma no contexto geral da escola, incitando atitudes, transformando a estrutura e provocando conflitos conceituais.

Consideramos que para escola excludente se transformar em escola inclusiva, são necessárias atitudes político-educacionais, em que o movimento no contexto da escola deve ser gerado a partir do bom entendimento sobre a inclusão e compreender o lugar desse serviço da Educação Especial, o AEE.

Existem muitas confusões e equívocos sobre o "como" realizar o serviço do AEE dentro da escola comum. Por isso, este texto vem elucidar inicialmente alguns aspectos procurando colaborar com a produção científica nessa área, em que o desenvolvimento e a aprendizagem humana tenham como foco o movimento relacional, tecido em rede, que oriente o diálogo e fomente a perspectiva inclusiva.

\section{REFERÊNCIAS}

\section{BRASIL. Política nacional de educação especial na perspectiva da educação}

inclusiva. Brasília: MEC; SEESP, 2011. Disponível em:

http://portal.mec.gov.br/index.php?option=com_docman\&view=download\&alias=1669

0 -politica-nacional-de-educacao-especial-na-perspectiva-da-educacao-inclusiva. Acesso em: 5 de out. 2017.

BRASIL. Decreto no 7.611, de 17 de novembro de 2011, Dispõe sobre a educação especial, o atendimento educacional especializado e dá outras providencias, Brasília.

BRASIL. Lei n. ${ }^{0}$ 13.146, de 6 de julho de 2015. Dispõe sobre a Lei Brasileira de Inclusão da Pessoa com Deficiência. Disponível em: http://www.planalto.gov.br/ccivil_03/_Ato2015-2018/2015/Lei/L13146.htm. Acesso em: 5 out. 2017. 
BRONFENBRENNER, U. A ecologia do desenvolvimento humano: experimentos naturais e planejados. Porto Alegre: Artes Médicas, 1979.

CARLETTO, A.; CAMBIAGHI, S. S. Desenho universal: um conceito para todos. Prefeitura da Cidade de São Paulo/Seped/CPA. Disponível em: maragabrilli.com.br/wpcontent/uploads/2016/01/universal_web-1.pdf. Acesso em: 5 out. 2017.

DAMÁZIO, M. F. M.; ALVES, C. B. Atendimento educacional especializado do aluno com surdez. São Paulo: Moderna, 2010.

FRANCO, M. A. R. S. A Pedagogia da pesquisa ação. Anais... Encontro Nacional de Didática e Prática de Ensino, 12, 2005, Curitiba. Curitiba: Endipe, 2005.

NUNES, C.; MADUREIRA, I. Desenho universal para a aprendizagem: construindo práticas pedagógicas inclusivas. Revista Educación y Pedagogía, Universidad de Lisboa, v. 22, n. 57, p. 93-109, mayo-ago. 2010. Disponível em:

https://ojs.eselx.ipl.pt/index.php/invep/article/view/84/html. Acesso em: 5 out. 2017.

\section{Como referenciar este artigo}

DAMAZIO, Mirlene Ferreira Macedo. Metodologia do Serviço do Atendimento Educacional Especializado em uma Perspectiva na Escola Regular. Revista on line de Política e Gestão Educacional, Araraquara, v. 22, n. esp. 2, p. 840-855, dez., 2018. EISSN:1519-9029. DOI: 10.22633/rpge.unesp.v22.nesp2.dez.2018.11916

Submetido em: 31/10/2018

Aprovado em: 20/11/2018 